\title{
How are PISA results related to adult life outcomes?
}

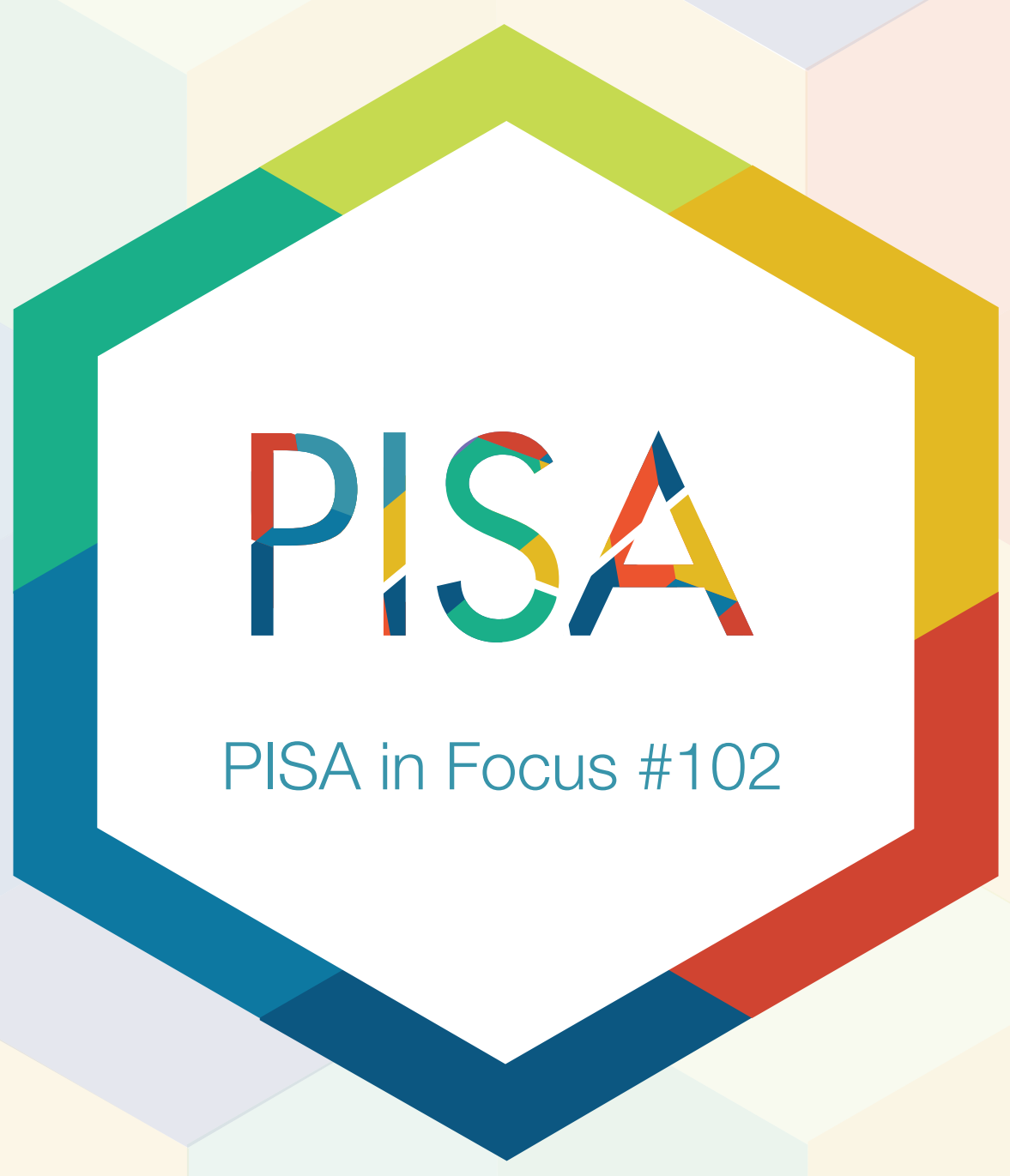




\section{How are PISA results related to adult life outcomes?}

- Four countries - Australia, Canada, Denmark and Switzerland - followed the students who sat the PISA 2000 or 2003 tests in the transition to adulthood.

- In all four countries, students who scored in the top quarter in the PISA reading assessment at age 15 were much more likely to have completed university by about age 25 compared to students who scored below them. High-performing 15-year-olds were also less likely to be out of the labour force and education by about age 25.

- In Canada and Denmark, performance in PISA explains almost half of the gap between advantaged and disadvantaged youth in the employment rates of skilled workers amongst 25-year-olds.

- PISA respondents who expected to work in a high-skilled job were between 10 (in Switzerland) and 40 (in Denmark) percentage points more likely to be doing so as young adults, compared to those who did not hold the same expectations when they were 15.

Every three years, the release of the PISA results provides a snapshot of the state of education around the world. For some countries, these results are a wake-up call, challenging policy makers to rethink their strategies and invest more in education. PISA also gives a glimpse into the future by providing reliable measures of the extent to which young adults are ready to participate fully in society.

What can the performance of 15-years-old students in 2018 tell us about the world in 2030? Will the high-performing countries have a competitive advantage over the low-performing countries? And does performance in PISA predict the life chances of individual students?

Some researchers have addressed these questions by modelling the relationship between performance in PISA (and other assessments of school systems) and indicators of economic prosperity, such as economic growth. For example, recent analysis finds that an increase in average PISA scores by 25 points over the next 20 years would result in an aggregate gain for OECD countries of USD 115 trillion over the lifetime of the generation born in 2010.

Another way to answer these questions is to look at how students who sat the PISA test at 15 were doing ten years later. The PISA report, Equity in Education: Breaking Down Barriers to Social Mobility, pursued this approach. It did so by using longitudinal data from the countries that surveyed the students who sat the PISA test during their transition to adulthood. The results were clear: students who did better in PISA at 15 tended to do better in early adulthood, according to several indicators, such as the final level of education they attained or the job they found when they left education.

Fifteen-year-old students who scored in the top quarter in reading were much more likely to complete university than students who scored in the bottom quarter. In Canada, $62 \%$ of students in the top quarter of reading performance at age 15 earned a university degree by age 25 - compared to just $9 \%$ of students in the bottom quarter (a 53 percentage-point difference). Performance in PISA is thus a good predictor of how students will do in formal education beyond 15. 


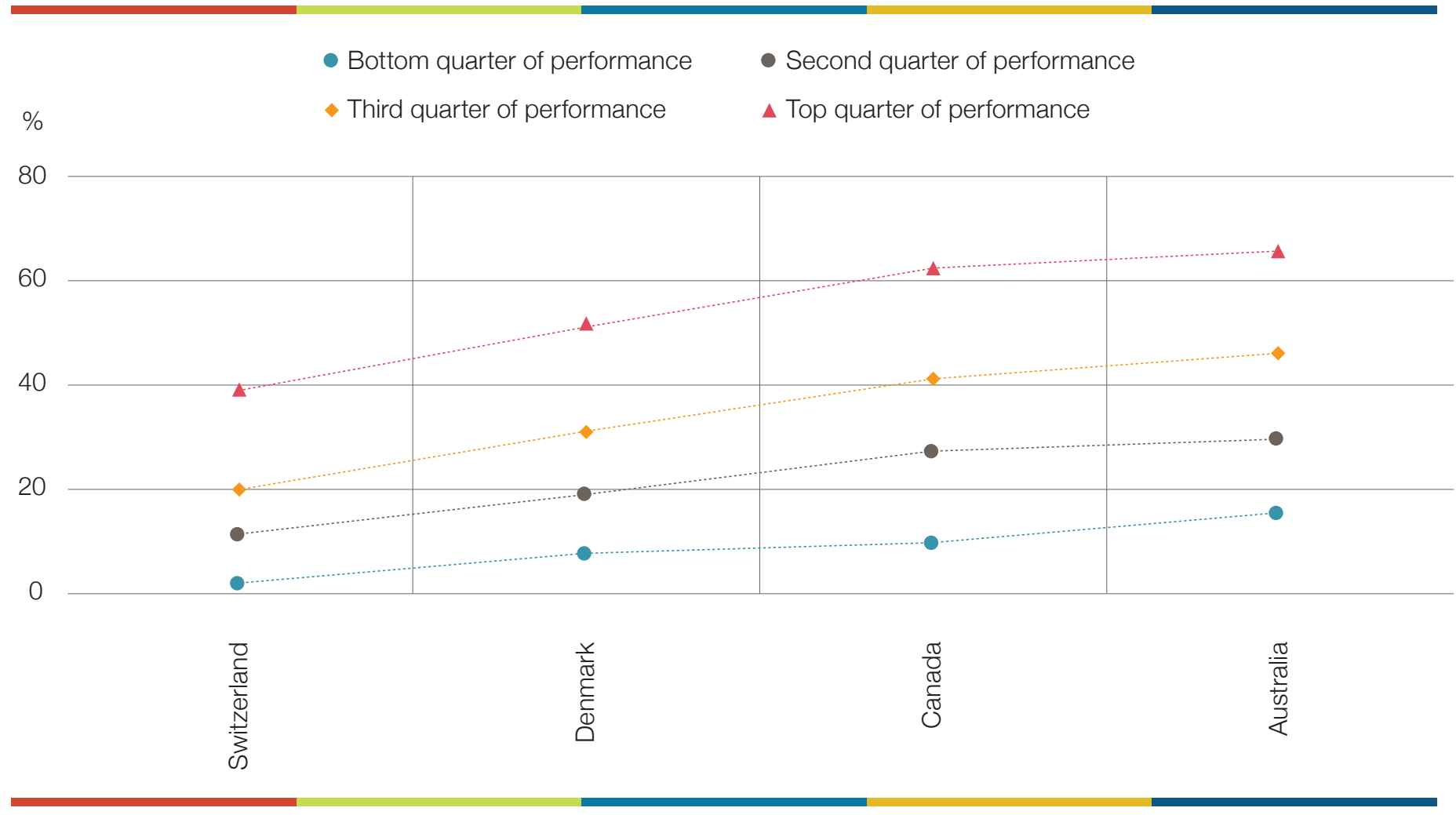

Notes: The difference between the top and the bottom quarters of reading performance are statistically significant in all countries.

Quarters of performance are computed for the final sample of each country's longitudinal data set.

Countries are ranked in ascending order of the percentage of students in the bottom quarter of reading performance.

Source: OECD (2018), Equity in Education: Breaking Down Barriers to Social Mobility, Figure 5.3; https://doi.org/10.1787/888933830766

PISA performance can predict more than the education prospects of 15-year-olds. Low-performers in PISA are also less likely to find a skilled, high-paying job. In Australia, only $14 \%$ of students who were in the bottom quarter of reading performance ended up in skilled employment at the age of 25 , while nearly $50 \%$ of students who were in the top quarter held a skilled job at that age.

Low performers were also more likely to end up out of the labour market entirely. In Canada, about $4 \%$ of students who were in the top quarter of reading performance when they were 15 were NEETs (Neither in Education nor in Employment or Training) at the age of 25; but this was the case for more than twice as many (9\%) students who scored in the bottom quarter of reading performance when they were 15 . In Australia, $7 \%$ of students who were in the bottom quarter of performance when they were 15 , but only $2 \%$ of students who were in the top quarter of performance were NEETs at the age of 25.

The factors that support success at schools, such as socio-economic status, are also likely to affect school-to-work transitions. Across the countries considered, students with tertiary-educated parents were between 7 and 20 percentage points more likely to be employed in skilled jobs at age 25 than students without tertiary-educated parents. Accounting for differences in PISA performance, however, reduces this gap to between 4 and 13 percentage points. Those disadvantaged students who did well in PISA were thus more likely to compete for skilled jobs later in life than disadvantaged students who did not overcome their disadvantage at school. 
Skilled employment, by parents' education and PISA reading performance at 15

Percentage-point difference in skilled employment between advantaged and disadvantaged youth at age 25

\% Dif.

- Difference before accounting for reading performance

22

- Difference after accounting for reading performance

17

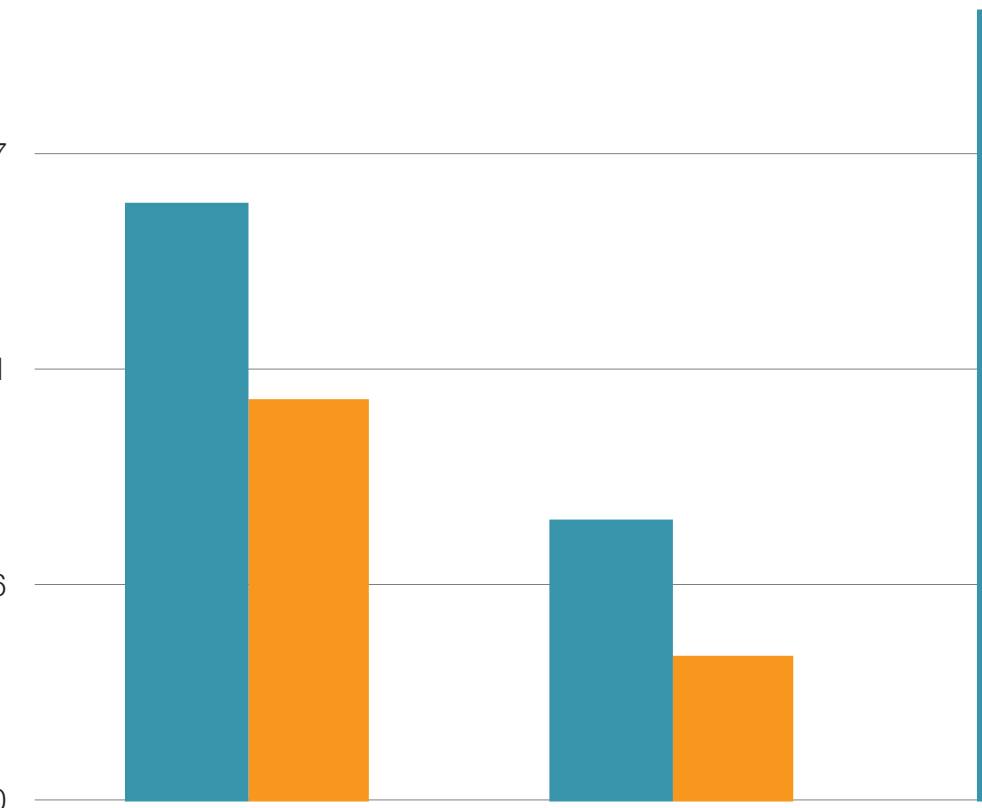

Australia

Canada

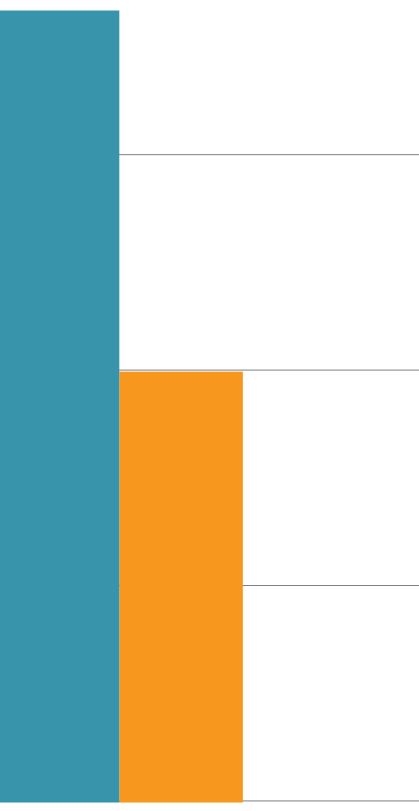

Denmark

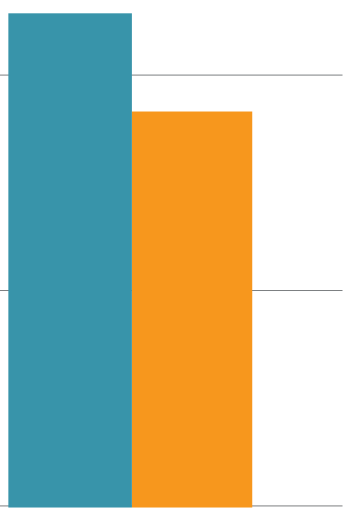

Switzerland

Notes: Skilled employment is defined as employment that requires tertiary education, ISCED level 5A or above.

Advantaged students are those with at least one tertiary-educated parent; disadvantaged students are those without a tertiary-educated parent.

Source: OECD (2018), Equity in Education: Breaking Down Barriers to Social Mobility, Figure 5.6; https://doi.org/10.1787/888933830823

PISA scores tell us how many 15-year-old students are proficient readers, and to what extent these students can solve real-life problems that require mathematics or science skills. However, through questionnaires, PISA also measures other important characteristics of the students, such as their attitudes towards learning, their learning strategies, their expectations for the future or their relationships with teachers and peers. Are the data PISA collects on students through its questionnaires also related to life outcomes in early adulthood?

The PISA report on equity identified several interesting relationships between students' responses to the questionnaires and their further education and employment careers. For example: in the four countries with available data, people who, as 15-year-old students, expected to work in a high-skilled job were more likely to be doing so as young adults than those who did not hold the same expectations when they were 15. In Australia, $40 \%$ of the 15-year-old students who expected to work in a high-skilled occupation, but only $20 \%$ of those who did not hold such expectations at 15 , were employed in such an occupation when they were 25 years old (this difference between the two groups of students remained large and significant even after accounting for differences in reading performance at age 15). As another example, students who reported in the PISA questionnaire that they invested greater effort and perseverance when facing difficulties at school were more likely to complete university than students who invested less effort and perseverance (students in the bottom quarter of that index). In Denmark, 35\% of students who had reported high levels of perseverance in school, but only $19 \%$ of students who had reported low perseverance in school, had completed university by the age of 25. 


\section{Student expectations and skilled employment}

Percentage-point difference in skilled employment rates at age 25 between those who did and those who did not expect to work in a skilled job when they were 15 years old

$\%$ Dif.

Difference before accounting for reading performance

$\square$ Difference after accounting for reading performance

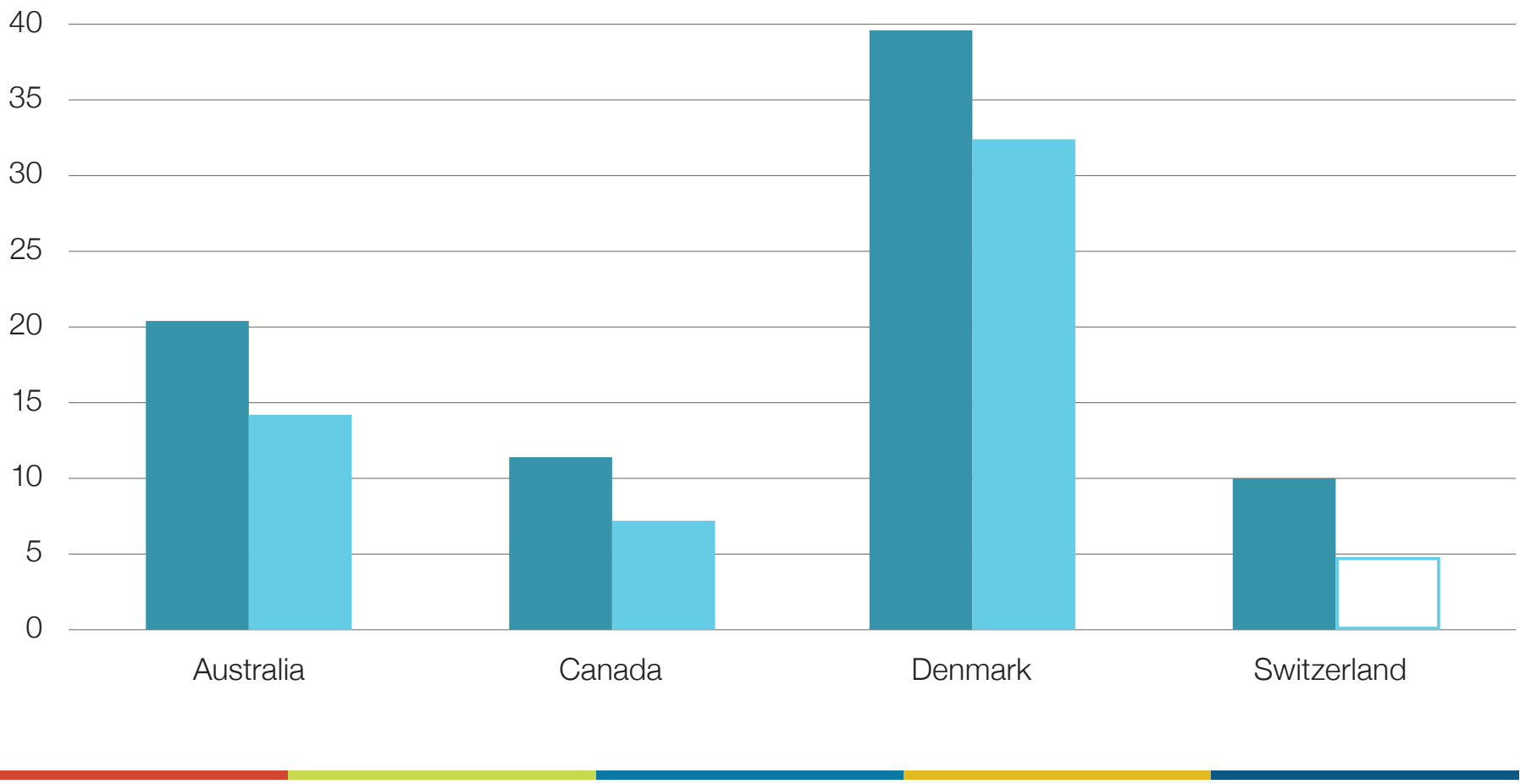

Notes: Statistically significant percentage-point differences after accounting for reading performance are shown in light blue.

All percentage-point differences before accounting for reading performance are statistically significant.

Source: OECD (2018), Equity in Education: Breaking Down Barriers to Social Mobility, Figure 5.9; https://doi.org/10.1787/888933830880

\section{The bottom line}

Performance in the PISA assessments, and what students say about themselves in the PISA questionnaires, represent valuable information about young people's life prospects. The release of the PISA 2018 results on 3 December 2019 is an opportunity to think about the future we want for our students - and the future they want for themselves - and how we can get there from here. 
For more information

\section{Contact:}

Mario Piacentini (Mario.Piacentini@oecd.org) or Bonaventura Pacileo (bonaventurapacileo@gmail.com)

See: OECD (2018), Equity in Education: Breaking Down Barriers to Social Mobility, OECD Publishing, Paris; https://doi.org/10.1787/9789264073234-en

OECD (2010), The High Cost of Low Educational Performance: The Long-run Economic Impact of Improving PISA Outcomes, OECD Publishing, Paris.

Coming next month: PISA 2018 Results

This paper is published under the responsibility of the Secretary-General of the OECD. The opinions expressed and the arguments employed herein do not necessarily reflect the official views of OECD member countries.

This document, as well as any data and map included herein, are without prejudice to the status of or sovereignty over any territory, to the delimitation of international frontiers and boundaries and to the name of any territory, city or area. 